\title{
Design Suggestions and Economic Analysis of Light Frame Shear Wall
}

\author{
Jie Bai*, Quanrui Luo, Feng Chen, Jiansong Yu \\ School of Civil Engineering, Guizhou University, Guiyang, 550003, China \\ *email: 147954114@qq.com
}

\begin{abstract}
Keywords: Light Frame Shear Wall, Shear wall, Design Suggestions, Economic Analysis
\end{abstract}
\begin{abstract}
Based on the results of the nonlinear parametric analysis interview, some design suggestions of light frame shear wall are put forward from studs spacing, height-width ratio of wall, the size and position of the openings. In addition, a real example is studied and analyzed on the design and optimization of light frame shear wall, with an economic analysis. The research shows that design suggestions and construction measurement can increase material utilization, economize on energy and material, improve produces condition and reduce construction period.
\end{abstract}

\section{Introduction}

The light wood structure is to use the uniform with wooden houses to withstand various plane and space effect of the stress system. With the application of light wood frame house in our country in recent years more and more widely, it is necessary for light wood structure system to carry out systematic theoretical and experimental research, in order to promote the development of the light timber structure system in our country. The main research contents of the study are mainly concentrated on the static or dynamic loading tests of shear walls. The main experimental parameters are test loading mode, panel size and material, connecting parts, Shear wall hole, etc., domestic scholars on the light timber structure of the overall seismic performance and shear wall of the lateral stiffness of the content to do a certain degree of research. For example, Shenton[1] test through the shear wall of wood structure that the static loading method is significantly greater than the wall loading method of dynamic loading. Cheung and Itani [2]considered the non-linear slip of the connected nail from the load-slip characteristics in the finite element analysis. Dolan[3] established a wooden shear wall analysis model, in the model using spring units to consider the panel and the panel and the sliding between the wooden frame. Doudak, G[4] through the experiment and the finite element software respectively to the light timber structure shear wall opening is different and the whole does not open the mechanical performance has carried on the test and the analysis. Nan-nan zhou and Min-juan He [5] [6] applied a unidirectional load to a certain shear wall to simulate and analyze the mechanical behavior and structural change of the shear wall.Based on the conclusion of the nonlinear finite element analysis of the light-weight timber structure shear wall model, the design proposal and construction requirements of the light timberframed shear wall are proposed. On this basis, the practical engineering case is taken as the economic object Analysis, the results that, in accordance with the proposed design recommendations proposed in this paper, can be effective materials, with better economy.

\section{Finite Element Analysis and Conclusions}

The main parameters were wall-to-column spacing, wall height-to-width ratio, wall opening, hole location, and axial compression. The main factors affecting the mechanical properties of woodwall, shear wall were obtained by parametric analysis on a large number of results. The influence law of the shear wall in the process of the stress control is determined. The results show that when the wall column spacing is the same, the lateral stiffness of the wall column decreases with the increase of the height-to-width ratio of the wall, and the change trend of the wall column remains almost constant when the height-to-width ratio is greater than 2; When the height-to-width ratio of the wall is the same, with the increase of the spacing of the pillars, the lateral stiffness decreases and the trend of the wall height-to-width ratio is basically the same. When the wall-column spacing is 
the same, the role of the wall column in the shear wall force decreases with the increase of the height-to-width ratio of the shear wall. When the height-to-width ratio of the shear wall is the same, The ratio of the force transfer of the column to the shear wall is reduced with the increase of the spacing between the columns. But when the height-to-width ratio of the shear wall is larger than 2, the proportion of force transmission is very small and with the wall column spacing changes in the trend is not.

\section{Design recommendations}

In the "Code for design of timber structures GB5005-2003" [7] in Chapter IX is on the light timber structure housing design, and the above parameters related to the study of the following points:

1) Clause 9.2.6 The setting of the wooden shear wall at point 5 stipulates that the height-to-width ratio of a single wall section is not greater than 2: 1 .

2) Clause 9.3.1 refers to the spacing of the wall column not to be greater than $600 \mathrm{~mm}$. Bearing wall's wall column size should be calculated to determine. Section 9.1.2 of the note refers to the common wall spacing of $300 \mathrm{~mm}, 400 \mathrm{~mm}, 500 \mathrm{~mm}, 600 \mathrm{~mm}$.

This paper, based on the current normative standard, combined with the above parametric analysis results, proposed some design parameters of the value proposition and limit requirements, with a view to light timber structure engineering design plays a reference role.

1) It is suggested that the height-to-width ratio of a single wall is not more than 2,the ratio of the hole area than not greater than $60 \%$, the ratio of hole width to wall width (S/ L) is not more than 2 .

2) When the height-to-width ratio of the wall is less than 0.4 , the recommended spacing of the pillars is in the range of $400 \mathrm{~mm}-600 \mathrm{~mm}$; when the wall height-to-width ratio is between 0.4 and 2 , the recommended spacing of the pillars is $200 \mathrm{~mm}-400 \mathrm{~mm}$.

\section{Practical engineering case analysis}

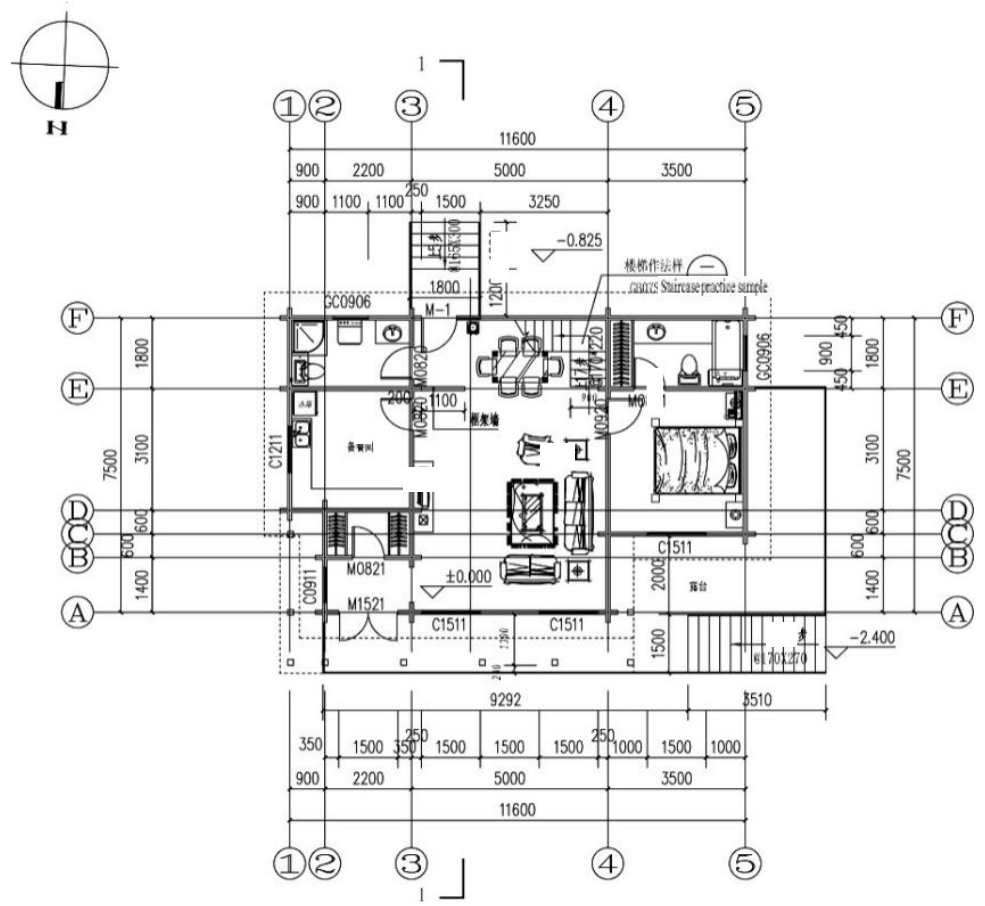

Fig. 1.13th floor plan of the first floor

The project is located in Xiashi Town, Guizhou Province-canoeing training base, with a total construction area of 4850.0 square meters. There are 15 different wooden houses. The 13th and 08th building structural design of the important components of wall columns for comparative analysis.13th and 08th light timber structure housing design of architectural layout shown in Figure.1 and Figure.2. 


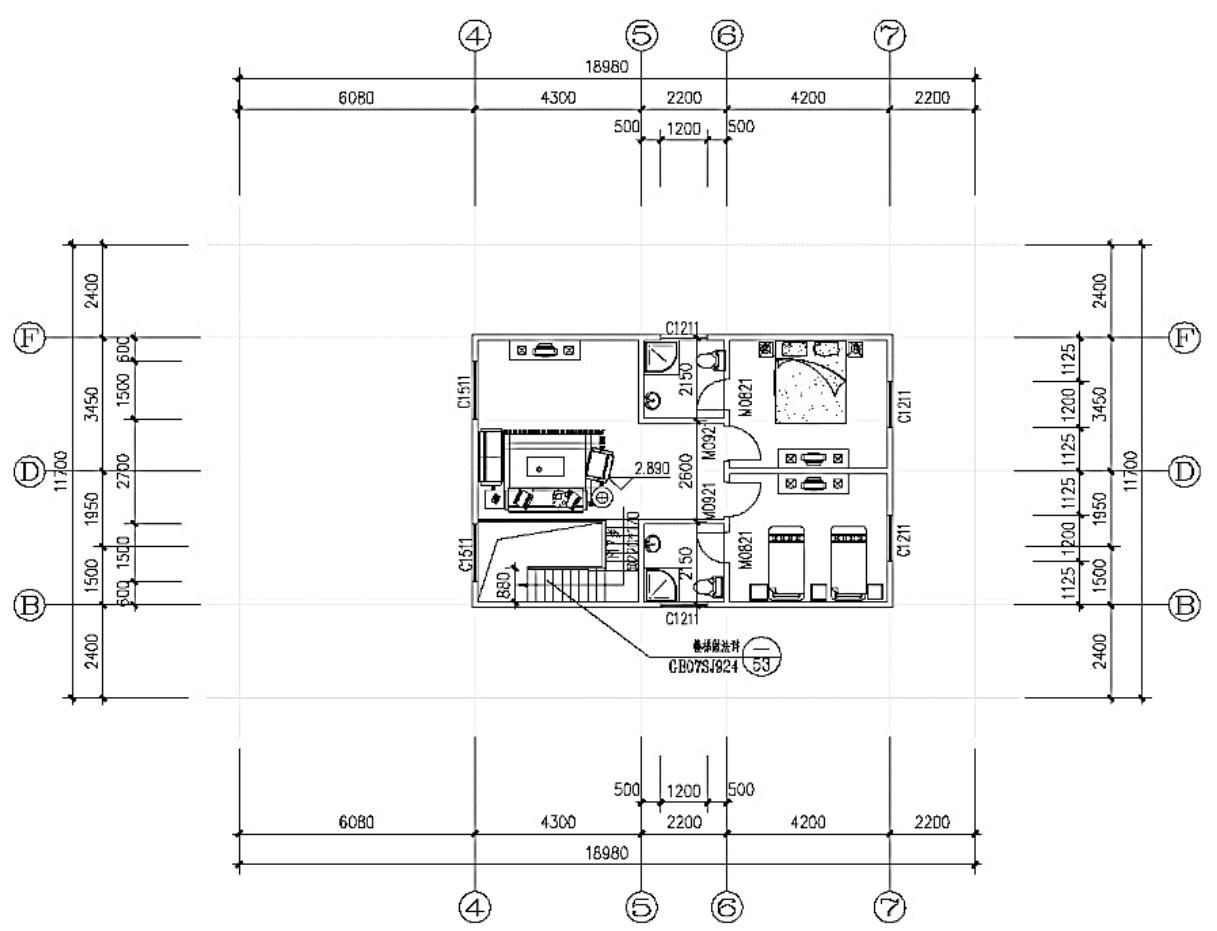

Fig.2. 08th two-story floor plan

A floor plan to take a more typical F-F shaft wall for comparative analysis:The center pillar column is designed according to the light timber structure in Chapter 9 of "Code for design of timber Structures GB5005-2003" [7]. The wall column is made of $40 \mathrm{~mm} \times 140 \mathrm{~mm}$ Chinese fir with strength grade TC11, $\mathrm{f}_{\mathrm{c}}=10 \mathrm{~N} / \mathrm{mm}^{2}, \mathrm{f}_{\mathrm{m}}=11 \mathrm{~N} / \mathrm{mm}^{2}$, wall column calculated length of $2.7 \mathrm{~m}$, wall column spacing of $400 \mathrm{~mm}$.F-F shaft wall length $\mathrm{L}$ is $10700 \mathrm{~mm}$ (deducting the length of doors and windows openings), wall height $\mathrm{H}$ is $2700 \mathrm{~mm}$, so $\mathrm{H} / \mathrm{L}$ is 0.25 . According to the actual situation of this wall a total of 23 wall columns.F-F axis wall height and width ratio of 0.25 less than 0.4 , so the wall column spacing can be $400 \mathrm{~mm}-600 \mathrm{~mm}$ this range, the original design using $400 \mathrm{~mm}$ wall column spacing in the proposed range. If the design of the value of the range to take the maximum value that is $600 \mathrm{~mm}$, The strength check table is as follows:

The vertical load on the external wall is designed to be: $25.89 \mathrm{KN} / \mathrm{m}$

The bearing design value of the single - wall column is: $\mathrm{N}=0.6 \times 25.89=15.534 \mathrm{KN}$

Wind load design value: $\mathrm{w}=0.202 \mathrm{KN} / \mathrm{m}^{2}$

According to the principle of equal strength, and according to the table of other trees in North America, the allowable pressure value of $40 \times 140 \mathrm{~mm}$ cross-section wall column is $15.6 \mathrm{KN}$ when the design value of wind load is $202 \mathrm{~N}$ meeting the requirements. So when the F-F wall columns spacing of $600 \mathrm{~mm}$, that is, a total of 15 wall columns, compared with the original design can save 8 wall columns. The B-B axis wall is compared with the typical two-layer plan:

The center pillar column is designed according to the light timber structure in Chapter 9 of the Code for design of timber Structure (GB5005-2003) [7]. The wall column is made of $40 \mathrm{~mm} \times$ $140 \mathrm{~mm}$ Chinese fir with strength grade TC11, fc $=10 \mathrm{KN} / \mathrm{mm} 2$,fm $=11 \mathrm{KN} / \mathrm{mm} 2$, wall column calculated length of $2.7 \mathrm{~m}$, wall column spacing of $400 \mathrm{~mm}$, a total of 19 wall columns.F-F shaft wall length $\mathrm{L}$ is $8000 \mathrm{~mm}$ (deducting the length of the door and window openings), wall height $\mathrm{H}$ is $2700 \mathrm{~mm}$, so $\mathrm{H} / \mathrm{L}$ is 0.34 less than 0.4 . If the spacing between the pillars is $600 \mathrm{~mm}$, check the following:

Strength checking:

$\frac{N}{A_{n} f_{c}}+\frac{M}{W_{n} f_{m}}=0.212<1.0$, Fulfil requirements;

Stable checking:

$\frac{N}{\varphi \varphi_{m} A_{0}}=1.734 \mathrm{~N} / \mathrm{mm}^{2}<f_{c}=10 \mathrm{~N} / \mathrm{mm}^{2}$,Fulfil requirements. 
The wall spacing of $600 \mathrm{~mm}$ column spacing applicable, this time a total of 13 wall columns, than the original design to save six wall columns.

Table 1 Comparison of wall material design for wall column design

\begin{tabular}{|l|l|l|l|l|l|}
\hline $\begin{array}{l}\text { Wood shear } \\
\text { wall number }\end{array}$ & $\begin{array}{l}\text { Wall } \\
\text { columns } \\
\text { spacing } \\
(\mathrm{mm})\end{array}$ & $\begin{array}{l}\text { Wood shear } \\
\text { wall area }(\mathrm{m} 2)\end{array}$ & $\begin{array}{l}\text { Wall columns } \\
\text { volume }(\mathrm{m} 3)\end{array}$ & $\begin{array}{l}\text { Amount of wall } \\
\text { columns per unit area } \\
(\mathrm{m} 3)\end{array}$ & $\begin{array}{l}\text { Unit area rate } \\
\text { of materials }\end{array}$ \\
\hline $\begin{array}{l}\text { Building 13th } \\
\text { F-F shaft wall }\end{array}$ & 400 & 50.49 & 0.63 & 0.012 & $33.33 \%$ \\
\cline { 2 - 5 } & 600 & 50.49 & 0.42 & 0.008 & \multirow{2}{*}{. }
\end{tabular}

Table 1 to meet the strength requirements of the case, and the design of the reception center wall column spacing compared to the larger rate of material, so that its economy is better. On the 08 units of the BB axis wall and 13 households in the FF axis wall, compared to the original design and the proposed design of the economic comparative analysis, the results shown below (the market price of 3600 Chinese fir wall studs Yuan / m3):

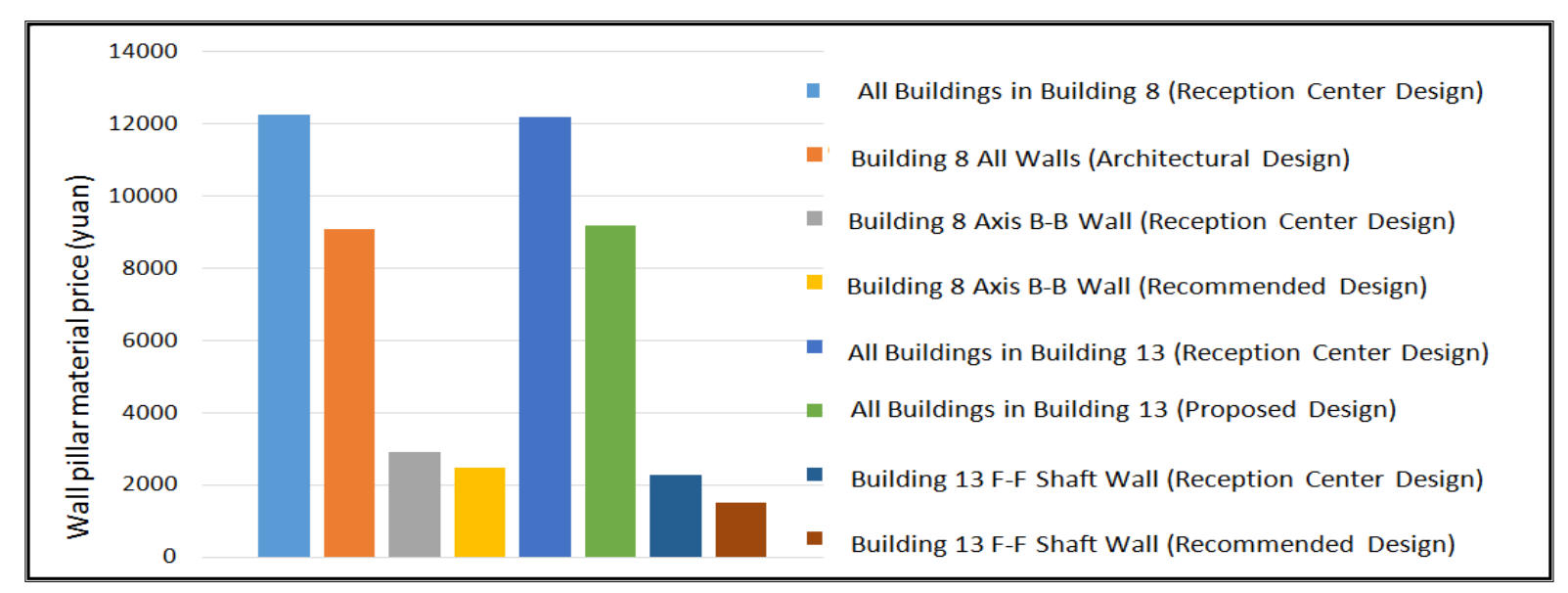

Fig.3. wall pillar material price economic comparison chart

From the above chart we can see that the design can not only save materials, but also can save the cost. The wall-column material prices calculated by the proposed design values in Fig. 3 are significantly lower than those at the reception center, and the proposed material price is lower than the price of the material designed by the reception center A quarter or so.

\section{Conclusion}

Through the result of structural design and economic comparison, the design proposal and construction requirement proposed in this paper can effectively save materials and meet the requirements of bearing capacity, and have good engineering economy.

\section{Acknowledgements}

This work was financially supported by Guizhou Province Science and Technology Foundation (QianKeHe J [2010] 2246).

\section{References}

[1] Dinehart D W, H W Shenton III. Comparisons of static and dynamic response of timber shear walls. Journal of Structural Engineering, 1998,124(6),686-695.

[2] Itani R Y, Tuomi R L, and McCutcheon W J. Methodology to evaluate racking resistance of nailed walls. Forest Products.J.,1983,32(1), 30-36.

[3] Dolan J D, Foschi R O. Structural analysis model for static loads on timber shear walls. J. Struct. 
Eng., 1991,117(3), 851-861.

[4] Doudak, G. ; Smith, I. ; McClure, G. ; Mohammad, M. ; Lepper, P. Tests and finite element models of wood light-frame shear walls with openings. J. Struct. Eng. and Mat.,2006 ,8( 4), 165174.

[5] Nan-nan zhou,Min-juan He. Analysis and Comparison of Finite Element Software for Shear Wall with Light timber Structure [J]. Special structure,2010,27 ( 1 ) :102-116.

[6] Nan-nan zhou, Min-juan He. Finite element analysis of light timber structure shear wall [J]. structural engineer,2010,26 ( 6 ) :37-41.

[7] Standard of the People 's Republic of China, Code for design of timber Structures (GB50052003). Beijing: China Building Industry Press.2003. 